\title{
The Drop-off and Pick-up Method: An Approach to Reduce Nonresponse Bias in Natural Resource Surveys
}

\author{
Shorna Broussard Allred • Amy Ross-Davis
}

Accepted: 29 October 2010

(C) Steve Harrison, John Herbohn 2010

\begin{abstract}
Forestry researchers frequently conduct surveys to assess woodland owner attitudes, behavior, behavioral intentions, and program adoption. However, the ability to utilize survey results in applied research is dependent upon how accurately the sample respondents reflect the reference population. One major issue in survey research is nonresponse bias. Nonresponse bias occurs when individuals do not respond to a questionnaire and is a concern because of the potential inability to make accurate inferences to a population based on responses. Researchers in this study compare two methods of questionnaire distribution (Drop-off/Pick-up and the Tailored Design Method) in terms of cost effectiveness and response rate. When compared to the Tailored Design Method (TDM), use of the Drop-off/Pick-Up (DOPU) method resulted in significantly higher response rates, provided an alternative method by which to determine survey eligibility, and had significantly higher survey implementation costs. The DOPU technique is an effective means to reduce potential nonresponse bias through increased response rate. When implementing the DOPU method, face-to-face contact and verbal communication with respondents permitted researchers to better determine eligibility than did leaving the questionnaire on the doorknob. Relying solely on respondents to indicate ineligibility on the survey instrument was not as effective as verbal confirmation of eligibility in the DOPU.
\end{abstract}

Keywords Woodland owners - Survey research · Survey methodology · Drop-off/pick up method · Nonresponse bias

\footnotetext{
S. B. Allred ( $\square)$

Department of Natural Resources, Cornell University, Ithaca, NY, USA

e-mail: srb237@cornell.edu
}

\author{
A. Ross-Davis \\ USDA Forest Service, Rocky Mountain Research Station, Forestry Sciences Laboratory, \\ 1221 South Main, Moscow, ID 83843, USA \\ e-mail: arossdavis@fs.fed.us
}




\section{Introduction}

Self-completion questionnaires are often used by forestry researchers as a means to obtain information from woodland owners for purposes of understanding decisionmaking behavior, evidence of program impact, attitudes, policy perspectives, or behavioral intention (for example, Butler and Leatherberry 2004; Skelton et al. 2005; Finley et al. 2006; Jennings and van Putten 2006; Janota and Broussard 2008). However, a common concern with data collection via self-completion mail questionnaires is nonresponse bias due to low response rates and non-coverage error associated with failure to include eligible households in the sampling frame. "Nonresponse error" is defined as "not getting everyone who is sampled to respond to the survey request" (Dillman et al. 2009, p. 17). Nonresponse bias can occur due to nonresponse error and is a function of response rate and the underrepresentation of particular types of population members (Wiseman 2003). Lindner and Wingenbach (2002) challenged researchers to address nonresponse error in their studies and noted that this is currently a significant threat to external validity.

One way to address nonresponse error rates in surveys is to develop and test strategies that have a positive and significant impact on response rates. This is especially critical because empirical evidence shows declining response rates over time to natural resource focused mail surveys (Connelly et al. 2003). Researchers have explored various techniques to increase response rates (see Dillman et al. 2009), including the use of incentives, multiple mailings, questionnaire design techniques, and alternative distribution strategies. One alternative questionnaire distribution method that has proven to increase response rates (relative to mail delivery) is the personal delivery or Drop-off and Pick-up (DOPU) self-administered questionnaire method (Douglas et al. 1970; Stover and Stone 1974; Lovelock et al. 1976; Mangione et al. 1982; Olsen et al. 1998; Melevin et al. 1999; Steele et al. 2001; Riley and Kiger 2002; Clark and Finley 2007). In this method, questionnaires are hand delivered to respondents at their home for later retrieval. In hand delivering the questionnaire, researchers have the opportunity to meet with respondents faceto-face. This technique has resulted in response rates as high as $93 \%$ in natural resource-related studies (Olsen et al. 1998).

The features described above to increase response rate do not diminish the importance of also conducting nonresponse bias analyses. Regardless of response rate, researchers should ensure that survey respondents accurately reflect the population surveyed. Procedures can be employed to assess the degree of nonresponse bias in a study such as comparing non-respondents to respondents, conducting an early versus late respondent analysis, or by contacting nonrespondents (Dillman et al. 2009; also see Miller and Smith 1983 for a discussion).

\section{Personal Delivery of Questionnaires}

Personal delivery of questionnaires has been used as an alternative to sending selfcompletion surveys in the mail. The DOPU method appeals to social psychological determinants of survey cooperation such as social exchange theory and balanced 
equity theory (Krannich et al. 1985; Bourke 1994; Krannich and Albrecht 1995; Olsen et al. 1998; Melevin et al. 1999; Theodori and Luloff 2000; Riley and Kiger 2002). Social exchange theory, in the context of social survey research, posits that respondents often complete questionnaires in return for current or future rewards (Dillman et al. 2009). In deciding whether to participate in a survey, respondents also want to strike a balance between costs (e.g. time, opportunity cost compared to other activities, difficulty, etc.) and benefits (e.g. satisfaction, financial incentives, ability to voice their opinion) (Childers and Skinner 1996). Research has also shown that people are more apt to cooperate if there is a legitimate authority associated with the request (i.e. sponsorship), if opportunities to participate in a survey are limited (scarce), and if the request comes from a person or entity that is liked or trusted (Dillman et al. 2009).

The DOPU survey methodology typically includes some or all of the following components. Often, notices are published in a local newspaper alerting residents to the study (Riley and Kriger 2002). Next, researchers attempt to make face-to-face contact with the eligible member of the household by hand delivering the questionnaire to the eligible individual or another person in the household or by leaving the questionnaire and cover letter on a doorknob if no one in the household is home at the time of delivery. Researchers return later to pick-up the questionnaire in-person and at a designated time (same day or 1 week later). Materials (addressed, stamped envelope and instructions) are left with the potential respondents so that they can mail back the completed questionnaire if an individual is not home at the time of pick-up (Melevin et al. 1999; Steele et al. 2001; Riley and Kiger 2002). Lastly, the DOPU methodology often includes the prompting of questionnaire completion through follow-up reminders (telephone or postcard by mail) (Melevin et al. 1999).

The DOPU method has several advantages compared to mail survey methods. First, there is the potential for personal contact (defined as face-to-face contact and verbal communication) between the respondent and a member of a research team if the potential respondent is home when the questionnaire is delivered. There is no personal contact if the potential respondent is not home when the survey is delivered. Face-to-face contact has the added benefit of researchers being able to explain, in person, the purpose of the study and the importance of the potential respondent's participation. The researcher can verbally communicate what the respondent would normally read in the questionnaire cover letter. Additionally, the researcher is able to determine whether the person meets the eligibility requirements of the particular survey (e.g. they are an owner of at least 10 acres of woodland). Also, the difficulty in returning the survey is reduced for the respondent because the research team member picks up the questionnaire versus the respondent having to remember to enclose it in an envelope and return by mail.

Face-to-face contact with the DOPU method has been shown to positively increase response rate over no face-to-face contact. For example, in an experiment comparing personal delivery methods, face-to-face contact at the time of questionnaire delivery and retrieval was associated with significantly $(P<.05)$ higher response rates (Melevin et al. 1999). These authors found that the response rate for those individuals who received the questionnaire personally was $66 \%$ 
compared to $54 \%$ for when the questionnaire was left with someone else in the household, and $17.4 \%$ for when the survey was left on the doorknob and no personal contact was made.

Follow-up after questionnaire drop-off is also important. In the Melevin et al. (1999) study telephone follow-up reminders to potential respondents increased response rate $(81 \%)$ over a postcard follow-up reminder $(44 \%)$. Thus, nonresponse was only $19 \%$ for the sub-sample receiving a telephone reminder; survey nonresponse was significantly $(P<.05)$ higher $(56 \%)$ for those that received the postcard reminder (Melevin et al. 1999). The use of a financial incentive coupled with personal follow-up did not impact response rate. When paid, the response rate was $50 \%$, regardless of whether a follow-up was conducted. Note that this response rate $(50 \%)$ is still higher than what was achieved when neither financial incentive nor follow-up were provided (35\%). Thus providing a financial incentive or personal follow-up can statistically increase response rate over not providing either of these options.

While the DOPU has the potential to increase survey response rates, reduce nonresponse bias, and increase the ability of researchers to determine eligibility, it is not without limitations. It can be difficult to determine whether the eligible individual actually completed the questionnaire (same limitation in mail surveys) and survey costs are increased by delivering questionnaires personally relative to mailing them (Mangione et al. 1982; Riley and Kiger 2002). In one study, costs of the DOPU method were found to be $\$ 16-\$ 21$ per questionnaire versus $\$ 6-\$ 8$ using the Tailored Design Method (description below) for mail surveys (Steele et al. 2001). Also, in previous research, the DOPU method has been implemented in small towns or densely populated areas-places where addressing systems are clear and where residents are potentially open to visitors (Steele et al. 2001). Another limitation of the DOPU method is that it is not ideal for locations where there are significant numbers of second-home owners as the researchers may not be able to effectively reach their desired sample population.

In this research, two survey methods are compared-the DOPU technique and the Tailored Design Method (TDM; Dillman et al. 2009), in terms of cost effectiveness and efficacy in increasing response rate. The TDM is a framework and set of strategies for survey design and implementation that was originally developed in the 1970's and continually refined based on evidence from a number of methodological experiments in survey design and implementation (Dillman et al. 2009). For postal mail survey implementation, the TDM typically involves 5 survey mailings sent at weekly intervals (advance notice letter, survey + cover letter, reminder postcard, 1st replacement survey + cover letter, and 2 nd replacement survey + cover letter) (Dillman et al. 2009).

With the prevalence of survey methods in private forest landowner research, knowledge can be advanced by learning about various methodological options available to forestry researchers. Results of this study can help to inform forest social science researchers that utilize survey research methods. Also, while DOPU methodological studies have been conducted with the general public, homeowner, working age, and working poor samples, there is little published research on the use of this technique with forest owners. The research objectives of the study were to: (1) determine the response rate differences for two survey methods (Tailored Design 
Method and Drop-Off/Pick-Up method), (2) determine whether face-to-face contact with potential survey respondents in the DOPU significantly increases response rate over no face-to-face contact, (3) determine the cost-effectiveness of the Tailored Design Method and the DOPU method, and (4) determine whether respondent dispositions (complete, refusal, undeliverable, nonrespondents, ineligible) differ between the TDM and DOPU methods.

\section{Research Methodology}

The overall study sought to explore central Indiana private woodland owners' attitudes and behaviors with regard to land, community, and forest management (see Ross-Davis and Broussard 2007). Within that study, a methodological experiment was conducted to determine whether higher response rates could be achieved by the DOPU questionnaire delivery method versus the postal mail method (Tailored Design Method). The study sites (described below) (Fig. 1) were also segmented by land cover (agriculture, forest, mixed) since that could potentially impact the saliency of a forestry-focused survey instrument.

\section{Methods and Site Description for the DOPU Experimental Group}

Two 23- $\mathrm{km}^{2}$ study sites in the Upper Wabash River Basin in north-central Indiana were selected for the application of the DOPU technique (Fig. 1). These sites are characterized by low population densities and relatively high forest cover for northcentral Indiana (Table 1). While most DOPU methodological studies sample in densely populated areas, in this study, researchers surveyed in rural areas where the

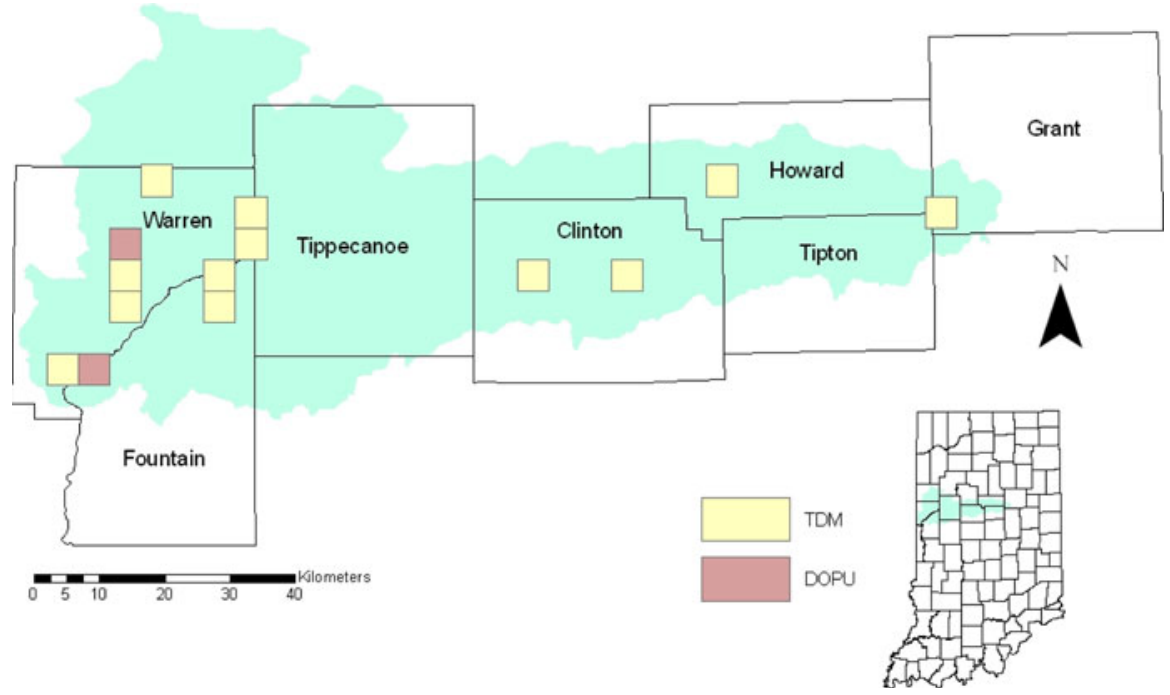

Fig. 1 County and watershed boundaries for Drop-Off and Pick-Up (DOPU) and Tailored Design Method (TDM) study sites in Indiana, USA 
Table 1 Population density, forest cover, sample size, and response rate for Drop-Off/Pick-up forested sites, Tailored Design Method mixed forested/agriculture landscape sites, Tailored Design Method forested sites, and Tailored Design method agricultural sites

\begin{tabular}{|c|c|c|c|c|}
\hline $\begin{array}{l}\text { Questionnaire delivery } \\
\text { method and landscape type }\end{array}$ & $\begin{array}{l}\text { Population density } \\
\text { (people } / \mathrm{km}^{2} \text { ) }\end{array}$ & $\begin{array}{l}\text { Forest } \\
\text { cover }(\%)\end{array}$ & $\begin{array}{l}\text { Total sample } \\
\text { Size (n) }\end{array}$ & $\begin{array}{l}\text { Response } \\
\text { rate }(\%)\end{array}$ \\
\hline 1: DOPU forested & 7.47 & 35.96 & 72 & 69.8 \\
\hline 2: DOPU forested & 7.65 & 25.62 & 53 & 72.0 \\
\hline DOPU response rate & & & 125 & $70.9^{\mathrm{a}}$ \\
\hline 1: TDM mixed & 17.61 & 22.15 & 49 & 52.2 \\
\hline 2: TDM mixed & 56.67 & 15.25 & 90 & 52.3 \\
\hline 3: TDM mixed & 10.42 & 26.71 & 67 & 42.2 \\
\hline 4: TDM mixed & 25.75 & 28.75 & 61 & 50.0 \\
\hline Overall TDM mixed & & & & $49.2^{\mathrm{a}}$ \\
\hline 1: TDM forested & 8.31 & 40.83 & 76 & 59.2 \\
\hline 2: TDM forested & 5.89 & 34.95 & 48 & 46.5 \\
\hline 3: TDM forested & 19.25 & 34.92 & 84 & 47.5 \\
\hline 4: TDM forested & 11.35 & 56.46 & 123 & 50.0 \\
\hline Overall TDM forested & & & & $51.1^{\mathrm{a}}$ \\
\hline 1: TDM agricultural & 8.63 & 1.86 & 24 & 42.1 \\
\hline 2: TDM agricultural & 17.83 & 10.83 & 67 & 54.7 \\
\hline 3: TDM agricultural & 31.37 & 1.59 & 34 & 48.4 \\
\hline 4: TDM agricultural & 6.52 & 4.12 & 14 & 50.0 \\
\hline Overall TDM agricultural & & & & $50.8^{\mathrm{a}}$ \\
\hline Overall TDM resp. rate & & & & $50.3^{\mathrm{b}}$ \\
\hline Overall DOPU resp. rate & & & & $70.9^{\mathrm{b}}$ \\
\hline
\end{tabular}

a ANOVA: $F=10.393, P=.002, \eta^{2}=0.757$ (Tukey post-hoc multiple comparisons: DOPU vs. TDM Mixed $P=0.003$, DOPU vs. TDM forested $P=0.004$, DOPU vs. agricultural $P=.002$ )

b ANOVA: $F=35.706, P<.001, \eta^{2}=0.865$

majority of woodland owners in Indiana reside. The DOPU method of survey delivery was only conducted at two sites due to the time and cost intensive nature of this method. Notices were published in the local newspaper of each community prior to questionnaire drop-off to alert local residents of the study. Questionnaires were packaged in clear plastic bags with a cover letter and packet of Eastern redbud (Cercis canadensis) seeds, a flowering tree native to Indiana, as an incentive. While all residents of these sites were included in the study, absentee landowners who owned land within the study site but resided elsewhere were excluded as we had no way of hand-delivering questionnaires to these individuals.

Researchers made face-to-face contact and verbally communicated with residents (if they were home) and determined eligibility before giving the questionnaire to them. Residents who indicated they did not own at least one acre of woodland were considered ineligible. A copy of the questionnaire and a cover letter were left on the front doorknob of all households in which no one was home at the time of delivery. The cover letter asked residents to indicate, by checking a box, if they did not own woodland and to leave the letter in the questionnaire package on their front 
doorknob for retrieval. For those residents who were eligible, the letter instructed them to leave the completed questionnaire on the front doorknob for retrieval. In each case, questionnaire retrieval was done during a 2 hour window 2 days following initial questionnaire delivery. Thus, residents could be present during the questionnaire pick-up if they so chose, or they could simply leave the completed questionnaire on their doorknob for retrieval.

On 21 February 2004, two teams of two researchers each distributed questionnaires throughout the first site. There were 72 households in the study site. Distribution took approximately $6 \mathrm{~h}$ including travel time (the site was approximately $40 \mathrm{~min}$ from the Purdue University West Lafayette campus). Between $3: 00 \mathrm{pm}$ and 5:00 pm on 23 February, two teams of two researchers retrieved questionnaires from those households to which questionnaires had been delivered. At those households where the questionnaire was not left by the resident for retrieval by the researcher, a type-written and hand-signed note on cardstock was left indicating that researchers would return between 3:00 pm and 5:00 pm on 25 February for questionnaire retrieval. If the questionnaire was still not left by the resident for retrieval, we would leave another note on cardstock asking the resident to mail in their completed questionnaire or their cover letter with the appropriate box checked to indicate that they did not own woodland using the stamped, selfaddressed envelope provided. This approach was repeated with the 53 households in the second site beginning on 6 March through 10 March. A total of 3 contacts were attempted for each individual in each of the 2 DOPU sampling sites.

\section{Methods and Site Description for the TDM Experimental Group}

The sites in which questionnaires were mailed according to the TDM are also located in the Upper Wabash River basin in Indiana (Fig. 1). Twelve study sites (each $23-\mathrm{km}^{2}$ ) were selected for investigation, four from each of three site types (i.e., sites characterized by land use attributes of (1) forest, (2) agriculture, or (3) mixed forest/agriculture) spanning seven counties in northern Indiana (Table 1). Addresses for all landowners who owned at least one acre of woodland in these study sites were obtained from property tax records located at the county assessors' offices which were cross-referenced with aerial photographs to ensure that selected properties contained at least 1 acre of woodland. The aerial photography method was used in all TDM sites to pre-determine eligibility (landowners with at least 1 acre of woodland) for the postal survey. Researchers cross-referenced property tax records with aerial photography to determine whether the land was actually forested. Also, the initial question on the TDM mail questionnaire gave sample members the opportunity to indicate whether they owned one acre of woodland. If they did not, they could check the box and mail back the questionnaire.

On 6 February 2004, a prenotification letter announcing the forthcoming arrival of the questionnaire was sent to all woodland owners in each of the 12 sites. The first questionnaire was sent on 23 February and was accompanied by a cover letter and a packet of Eastern redbud seeds as an incentive. On 3 March, a thank you/ reminder postcard was sent to all woodland owners. On 10 March, a second copy of the questionnaire was sent to all nonrespondents and was accompanied by a 
modified cover letter. Finally, on 26 March, a third copy of the questionnaire accompanied by a cover letter was sent to all remaining nonrespondents. Mailings were sent using first-class postage.

\section{Analysis Methods}

Descriptive statistics, chi-square analyses, and ANOVA (with Tukey post-hoc tests) were used to compare questionnaire response rates and questionnaire disposition. Questionnaire disposition is based on the ultimate outcome of each questionnaire: completed questionnaire, deceased, ineligible, refused to complete questionnaire, questionnaire was undeliverable, and did not respond to questionnaire (nonrespondents). Phi $(\varphi)$ and eta $(\eta)$ were used to examine effect sizes for statistical tests (Vaske et al. 2002). In calculating response rates in this study, Response Rate $6^{1}$ from the American Association for Public Opinion Research Standard Definitions publication was used (American Association for Public Opinion Research 2008). T-tests were used to compare item nonresponse (how many questions are completed versus left blank) between DOPU and TDM.

\section{Results}

\section{Nonresponse Bias Analysis}

To examine potential nonresponse bias, a number of property and tax features (e.g., total forest acreage, home site value, and true tax value of the land) were compared between respondents and non-respondents (refusals and unknowns). The only characteristic by which non-respondents differed from respondents related to total acreage enrolled in the Classified Forest Program. Respondents had significantly more acreage enrolled in the Classified Forest Program than did nonrespondents $(t=-2.309 ; P=0.021)$.

\section{Drop-Off and Pick-Up Survey Method (DOPU)}

\section{Site 1}

Of the 72 residents in households in this site, 23 were ineligible (i.e., residents did not own at least one acre of woodland), and six were undeliverable (i.e., residents did not occupy the home during the time of the study as evidenced by the questionnaire left untouched on the doorknob upon return) (Tables 1, 2). Out of the remaining 43 households with individuals who were potentially eligible, 30 either left for retrieval or returned via mail completed questionnaires, for a final response rate of $69.8 \%$ (Table 1). Response rate following first retrieval (23 February) was

\footnotetext{
1 The response rate was calculated by researchers using the following formula: $\mathrm{RR} 6=(\mathrm{I}+\mathrm{P}) /$ $(\mathrm{I}+\mathrm{P})+(\mathrm{R}+\mathrm{NC}+\mathrm{O})$, where $\mathrm{I}=$ Complete response, $\mathrm{P}=$ Partial response, $\mathrm{R}=$ Refusal, $\mathrm{NC}=$ Non-contact, $\mathrm{O}=$ Other non-contact.
} 
Table 2 A comparison of dispositions across DOPU and TDM methods (see footnote a) and DOPU and TDM (forested sites only) (see footnote b) methods

\begin{tabular}{lccc}
\hline & DOPU (forested) $\mathrm{n}(\%)$ & TDM (overall) $\mathrm{n}(\%)$ & TDM (forested) ${ }^{\mathrm{b}} \mathrm{n}(\%)$ \\
\hline Complete or partial & $48(38.4)$ & $348(47.2)$ & $160(48.3)$ \\
Deceased & $0(0)$ & $3(0.4)$ & $1(0.3)$ \\
Ineligible & $45(36.0)$ & $19(2.6)$ & $3(0.9)$ \\
Refusal & $6(4.8)$ & $12(1.6)$ & $5(1.5)$ \\
Undeliverable & $12(9.6)$ & $23(3.1)$ & $13(3.9)$ \\
Nonrespondents & $14(11.2)$ & $332(45.0)$ & $149(45.0)$ \\
Total & $125(100.0)$ & $737(100.0)$ & $331(100.0)$ \\
\hline
\end{tabular}

Percentages of total are in parentheses (percentages represent each disposition category, not response rate)

${ }^{a} \chi^{2}=72.581, P<0.001, \varphi=0.379$ (DOPU forested compared to TDM overall, cell counts less than 5 excluded from analysis)

b $\chi^{2}=106.92, P<0.001, \varphi=0.482$ (DOPU forested compared to TDM forested, cell counts less than 5 excluded from analysis)

$39.5 \%$ and following second retrieval (25 February) was $58.1 \%$. The additional 5 completed questionnaires that were mailed in raised the overall response rate to $69.8 \%$. The subsample of residents that researchers spoke with to determine eligibility at the time of questionnaire drop-off $(n=37)$, had a response rate of $61.9 \%$. The response rate for the subsample with no personal contact $(n=35)$ was 77.3\%. For this site, personal contact during drop-off did not seem to positively influence response rate.

\section{Site 2}

Of the 53 residents in households in this site, 22 were ineligible, and 6 were undeliverable (Tables 1,2). Out of the remaining 25 households with individuals who were potentially eligible, 18 either left for retrieval or returned via mail completed questionnaires, for a final response rate of $72.0 \%$. (Table 1) Response rate following first retrieval ( 8 March) was $40.0 \%$ and following second retrieval (10 March) was $60.0 \%$. Following receipt of an additional 3 mailed-in questionnaires, the overall response rate increased to $72.0 \%$. For the subsample of residents with whom researchers spoke with face-to-face to determine eligibility during questionnaire drop-off $(n=26)$, the response rate was $84.6 \%$. The response rate for the subsample with no personal contact $(n=27)$ was $58.3 \%$. For this site, personal contact during questionnaire drop-off had a positive impact on response rate.

\section{Tailored Design Survey Method (TDM)}

\section{Mixed Sites}

Of the 267 households who owned land in the four mixed land cover sites, 12 were ineligible, ${ }^{2} 1$ individual had passed away, 3 refused to complete the survey, and 4 
surveys were undeliverable (Tables 1, 2). Out of the remaining 246 households, 123 returned completed questionnaires. Response rate for these sites ranged from 42.2 to $52.3 \%$, with an overall response rate of $49.2 \%$. (Table 1 ).

\section{Forested Sites}

Of the 331 households who owned land in the four forested land cover sites, 3 were ineligible, 1 individual passed away, 5 refused to complete the survey, and 13 surveys were undeliverable (Tables 1, 2). Out of the remaining 309 households, 160 returned completed questionnaires. Response rate for these sites ranged from 46.5 to $59.2 \%$, with an overall response rate of $51.1 \%$ (Table 1 ).

\section{Agricultural Sites}

Of the 139 households who owned land in the four agricultural land-use sites, 4 were ineligible, 1 individual passed away, 3 refused to complete the survey, and 6 surveys were undeliverable (Tables 1,2). Out of the remaining 125 households, 65 returned completed questionnaires. Response rate for these sites ranged from 42.1 to $54.7 \%$, with an overall response rate of $50.8 \%$ (Table 1 ).

There was no statistically significant effect of site type (i.e., forest, agriculture, or mixed forest/agriculture) on response rate $\left(F=0.163, P=0.852, \eta^{2}=0.187\right)$. The distribution of dispositions for the TDM was also independent of site type $\left(\chi^{2}=15.452, P=0.116,=\varphi=0.144\right)$.

\section{DOPU and TDM Method Comparison}

Response rate for the DOPU experimental group (70.9\%) exceeded that of the TDM group $(50.3 \%)$, both overall (Table 1) and when compared to the TDM forested sites $(51.1 \%)$ to which DOPU sites were most physically similar $(F=20.920$, $P=.010, \eta^{2}=0.839$ ). When comparing dispositions between the DOPU and TDM sites, there was a statistically significant difference in the proportions (Table 2). This relationship was also true when comparing the DOPU sites and the TDM forested sited (Table 2). Also, an average of $90.49 \%$ of the core questions on the survey instrument were completed by respondents in the TDM experimental groups and an average of $90.66 \%$ of the core survey questions were completed by respondents in the DOPU experimental group $(t=-0.092, P=0.926)$. Thus, there was no statistically significant difference in item nonresponse (respondents leaving questions on the survey blank) between the TDM and DOPU survey methods.

Results are inconclusive regarding response rate impacts of face-to-face contact and verbal communication during the delivery of questionnaires in the DOPU. In DOPU site 2, personal contact resulted in a statistically significant difference in response rate. However, in DOPU site 1 researcher face-to-face contact and verbal communication with the potential respondent did not have a statistically significant

\footnotetext{
${ }^{2}$ Although property tax records and aerial photographs were used to identify all woodland owners in the study sites, some individuals indicated they no longer owned woodland and thus were deemed ineligible.
} 
Table 3 Disposition according to whether the survey was hand delivered or left on the resident's doorknob (see footnote a)

Percentages of total are in parentheses

a $\chi^{2}=3.931, P=0.036$, $\varphi=.177$

\begin{tabular}{llc}
\hline & $\begin{array}{l}\text { Hand delivered } \\
\text { to resident } \mathrm{n}(\%)\end{array}$ & $\begin{array}{l}\text { Left on } \\
\text { doorknob n }(\%)\end{array}$ \\
\hline Complete or partial $^{\prime}$ & $24(38.1)$ & $24(38.7)$ \\
Ineligible $^{1}$ & $28(44.4)$ & $17(27.4)$ \\
Refusal & $5(7.9)$ & $1(1.6)$ \\
Undeliverable & $1(1.6)$ & $11(17.7)$ \\
Nonrespondents & $5(7.9)$ & $9(14.5)$ \\
Total & 63 & 62 \\
\hline
\end{tabular}

Table 4 Total cost for implementation of the TDM and DOPU methods of survey distribution broken down by costs per household and cost per respondent

\begin{tabular}{llll}
\hline Survey method & Total cost $(\$)$ & Cost per household $(\$)$ & Cost per respondent (\$) \\
\hline TDM & $4,913.43$ & 6.67 & 14.12 \\
DOPU & $1,206.62$ & 9.65 & 25.14 \\
\hline
\end{tabular}

The TDM calculation is based on the preparation, printing, and mailing of 737 12-page color questionnaires and associated Purdue University stationary and first class postage; the DOPU calculation is based on the preparation and printing of 125 12-page surveys and cover letters, 125 plastic bags, 23 $9 \times 12$ envelopes and stamps, travel, and 3 research assistants for questionnaire distribution and retrieval

impact on response rate. Also, the site level differences in response rate by faceto-face contact disappeared when data from the two DOPU sites were combined (Table 3). Verbal communication and face-to-face contact with the potential respondent during questionnaire drop-off did allow the researcher to better determine eligibility than did simply leaving the questionnaire on the doorknob if they were not home (Table 3).

Within the DOPU method, researchers were not able to pre-determine eligibility as with the TDM. Researchers relied on the verbal communication with the potential respondent during questionnaire delivery (if they were home) to ascertain eligibility. Survey researchers were able to ask the members of the sample if they owned at least 1 acre of woodland or they could check the box on the cover letter indicating that they did not own at least one acre of woodland. Face-to-face contact and verbal communication in the DOPU method revealed a significantly greater proportion of the sample as ineligible when compared to those for which there was no face-to-face contact (Table 3). Leaving the questionnaire on potential respondent's doorknob led to a significantly $(P<.05)$ greater proportion of questionnaires coded as undeliverable (no one ever picked up the questionnaire) (Table 3). Thus relying solely on the respondent to notify the researcher of ineligibility by checking the box on the survey is not as effective in determining eligibility as verbal face-to-face communication during face-to-face contact during questionnaire drop-off.

The cost per household of the DOPU method was almost $50 \%$ higher than the total cost for the TDM (Table 4). Costs were calculated per sample member household and per actual respondent for the two survey methods. For the TDM costs include labor (staff time to stuff envelopes for mailing), materials (envelopes, paper, labels, etc.), questionnaire printing, and mailing (outgoing and incoming postage). 
For the DOPU costs calculations include labor (staff time to prepare questionnaire packets), materials (envelopes, paper, labels, plastic bags, etc.), questionnaire printing, questionnaire delivery, and incoming mail postage. When total costs were standardized to reflect the cost per respondent, the cost for implementation of the DOPU method was almost double the cost of the TDM (Table 4).

\section{Discussion}

Use of the DOPU method in this study had several primary outcomes when compared to TDM. The survey response rate was significantly higher with DOPU when compared to TDM. In fact, the use of the DOPU method increased the response rate by $20.6 \%$ overall relative to the TDM. For TDM forested sites, which most closely resemble the DOPU sites in that they are characterized by low population densities and relatively high forest cover, use of the DOPU method increased response rate by $19.8 \%$ overall. The increase in response rate is likely due to the questionnaire delivery method and the salience in communities with higher forest cover since the survey topic was forestry-related.

In previous DOPU studies, follow-up after survey drop off and attempted retrieval resulted in significantly higher response rates when compared to providing no follow-up. In this study, researchers used two follow-ups: a post-card 2 days after the initial questionnaire drop-off and a post-card and a pre-paid envelope on the 3 rd and last visit which occurred 2 days after 2 nd visit. This likely contributed to the high response rate in the DOPU site and further corroborates previous research on the importance of follow-up after questionnaire drop-off.

Within the DOPU, researchers were able to determine woodland owner eligibility by verbally communicating with the potential respondent. However, there were no statistically significant differences in response rate regardless of whether there was face-to-face contact when delivering the DOPU questionnaire. Nevertheless, response rates were still significantly higher for the DOPU than postal mail delivery. This is likely due to the novelty of the DOPU delivery method. The color questionnaire is in a clear plastic bag on the potential respondent's doorknob which is more conspicuous than an envelope received in the mail. Because the questionnaire is left on their front door where it is easily visible, we speculate that it is subsequently more likely to be read and completed by the respondent. Even when there is no face-to-face contact, it is plausible that a questionnaire left by personal delivery has a greater chance of being completed than a questionnaire received by postal mail. Future research should examine the respondent motivations for questionnaire completion in the DOPU to accurately determine why personal delivery is associated with higher response rates when compared to mail delivery.

The DOPU method is an ideal survey method in cases where the researcher wants to increase respondent-researcher interaction (Steele et al. 2001). This was the case in this study as researchers were establishing a long-term research project in the study region. The DOPU method of questionnaire distribution was a way to personally interact with woodland owners in the area, something that would not have been possible with a traditional mail or even telephone survey. This method 
allowed the researcher to develop an understanding of the context for the research that the survey sought to inform (i.e., to explore private woodland owners' attitudes and behaviors with regard to land, community, and forest management) by personally visiting the communities and meeting with woodland owners. Another demonstrated benefit of this interaction was a more accurate disposition determination for a greater proportion of the sample for the DOPU.

The increased response rates and other associated benefits with this delivery method come at a significant financial cost. The cost per household of the DOPU method was almost 50\% higher than that of the TDM. For the actual cost per respondent, the cost for implementation of the DOPU method was almost double that of the TDM. The costs reported for both survey approaches do not incorporate pre-testing the questionnaire or data entry and analysis (these costs were same for each method). While the DOPU has a higher financial cost, there is much that can be gained from verbal communication with potential respondents. This may be important if you are conducting a study with a community in which you are seeking to build or sustain long-term relationships.

For forest social scientists, survey research can be an important means by which to gather data about woodland owner populations. In implementing surveys, the DOPU technique is an effective means to reduce nonresponse bias through increased response rate. Additionally, face-to-face contact in the DOPU can allow for a more thorough estimate of survey ineligibility than delivering the questionnaire without that contact. Lastly, the face-to-face and verbal contact, while brief, can aid in relationship building and the raising the profile of a research project in a community.

Acknowledgments The authors wish to thank Professor Don Dillman for his insightful review of this manuscript and former Purdue University Undergraduate Research Assistants Jaclyn McClead, Melissa Sharkis, and Bianca Whitaker for their assistance in delivering and collecting surveys.

\section{References}

Bourke L (1994) Economic attitudes and responses to citing hazardous waste facilities in rural Utah. Rural Sociol 59:485-496

Butler BJ, Leatherberry EC (2004) America's family forest owners. J For 102(7):4-9

Childers TL, Skinner SJ (1996) Towards a conceptualization of mail survey response behavior. Psychol Market 13(2):185-209

Clark WA, Finley JC (2007) Contracting meter readers in a drop-off/pick-up survey in Blagoevgrad, Bulgaria. Soc Nat Resour 20(7):669-673

Connelly N, Brown TL, Decker DJ (2003) Factors affecting response rates to natural resource-focused mail surveys: empirical evidence of declining rates over time. Soc Nat Res 16(3):541-549

Dillman DA, Smyth JD, Christian LM (2009) Internet, mail, and mixed-mode surveys: the tailored design method. Wiley, Hoboken 499 pp

Douglas S, Westley BH, Chaffee S (1970) An information campaign that changed community attitudes. Journal Q 47:479-497

Finley AO, Kittredge DB Jr, Stevens TH, Schweik CM, Dennis DC (2006) Interests in cross-boundary cooperation: identification of distinct types of private forest owners. Forest Sci 52(1):10-22

Janota JJ, Broussard SR (2008) Examining private forest policy preferences. For Policy Econ 10(3):89-97

Jennings SM, van Putten IE (2006) Typology of non-industrial private forest owners in Tasmania. Small Scale For Econ Manag Policy 5(1):37-56 
Krannich RS, Albrecht SL (1995) Opportunity/threat responses to nuclear waste disposal facilities. Rural Sociol 60(3):435-453

Krannich RS, Greider T, Little RL (1985) Rapid growth and fear of crime: a four-community comparison. Rural Sociol 60:435-453

Lindner JR, Wingenbach GJ (2002) Communicating the handling of nonresponse error in Journal of Extension Research in Brief articles. J Exten 40(6):6RIB1 [on-line]

Lovelock CH, Stiff R, Cullwick D, Kaufman IM (1976) An evaluation of the effectiveness of drop-off questionnaire delivery. J Market Res 13:358-364

Mangione TW, Hingson R, Barrett J (1982) Collecting sensitive data: a comparison of three survey strategies. Sociol Methods Res 10(3):337-346

Melevin PT, Dillman DA, Baxter R, Lamiman CE (1999) Personal delivery of mail questionnaires for household surveys: a test of four retrieval methods. J Appl Sociol 16:69-88

Miller LE, Smith KL (1983) Handling nonresponse issues. J Exten 21(5). Available at: http:// www.joe.org/joe/1983september/83-5-a7.pdf [On-line]

Olsen S, Amundsen DA, Anderson D, Guy S (1998) Community interest survey to plan a botanical center. J Exten 36(6). Available at http://www.joe.org/joe/1998december/tt2.html

Riley PJ, Kiger G (2002) Increasing survey response: the drop-off/pick-up technique. Rural Sociol 22:6-10

Ross-Davis A, Broussard SR (2007) A typology of family forest owners in North-Central Indiana. North J Appl For 24(4):282-289

Skelton P, Josiah SJ, King JW, Brandle JR, Helmers GA, Francis CA (2005) Adoption of riparian forest buffers on private lands in Nebraska, USA. Small Scale For 4(2):185-203

Steele J, Bourke L, Luloff AE, Liao P-S, Theodori GL, Krannich RS (2001) The drop-off/Pick-up method for household survey research. J Commun Develop Sociol 32(2):238-250

Stover RV, Stone WJ (1974) Hand delivery of self-administered questionnaires. Public Opin Q 37:284-287

The American Association for Public Opinion Research (2008) Standard definitions: final dispositions of case codes and outcome rates for surveys, 5 th edn. AAPOR, Lenexa

Theodori GL, Luloff AE (2000) Urbanization and community attachment in rural areas. Soc Nat Resour 13(5):399-420

Vaske JJ, Gliner JA, Morgan GA (2002) Communicating judgements about practical significance: effect size, confidence intervals and odds ratios. Hum Dimens Wildl 7(4):287-300

Wiseman F (2003) On the reporting of response rates in Extension research. J Exten 41(3). Available at: http://www.joe.org/joe/2003june/comm1.php [on-line] 